\title{
Keragaman Intensitas Serangan Hama Penggerek Buah Kopi (Hypothenemus hampei ferrari) Pada Beberapa Sentra Produksi Kopi Robusta di Provinsi Lampung
}

\section{Diversity of Intensity of Pest Attack Coffee Borrer (Hypothenemus hampei ferrari) on Some of Robusta Coffee Production Center in Lampung Province}

\section{Ovy Erfandari*, Hamdani, Dedi Supriyatdi}

${ }^{1}$ Lampung State Polytechnic / Program study of Plantation Crop Production

*E- mail : ovyerfandari@ polinela.ac.id

\begin{abstract}
Coffee fruit borer (Hypothenemus hampei Ferrari) is one of the main pests in coffee plants. This pest can cause damage such as undeveloped fruit, become turns reddish yellow and eventually falls, as well as hollow fruit which ultimately results in a decrease in the quantity and quality of production. In order to formulate and apply the concept of $H$. hampei pest control in an integrated manner, information on the diversity of attack levels needs to be known so that it can be prioritized and mapped control techniques to be applied. Therefore it is necessary to conduct research on "The Diversity Intensity of Coffee Fruit Powder (H. hampei) Pests in Several Robusta Coffee Production Centers in Lampung Province. The study was conducted in the districts of West Lampung, Tanggamus, North Lampung, and Way Kanan, from April to September 2019. Sampling was carried out by random method based on the area (Area Random Sampling). Samples are taken based on the harvest period in the selected sub-district within a predetermined district area. Sampling was repeated three times. In each district three farmers were selected in three sub-districts who were harvesting. In the pile of selected farmers' harvests coffee samples are taken using a bowl. The number of coffee fruits taken is counted with the number of holes $(A)$ and no holes $(B)$. Then the percentage or level of attack is calculated by using the following formula $\frac{A}{A+B} \times 100 \%$. Sampling of selected farmers was carried out three times. Research data were analyzed with variance using Fisher's test. The median value of the treatment was compared with the LSD test with $\alpha=0.05$. In addition, the temperature and height data collected from the research location were sourced from the BMKG of Lampung, then a regression analysis was conducted to determine the tendency of the relationship between the level of attack with the height and the temperature of the environment.
\end{abstract}

Keywords: Fruit Borer, Coffee Plant, Hypothenemus hampei Ferrari.

Disubmit: 21 Mei 2019; Diterima: 21 Oktober 2019; Disetujui: 02 Desember 2019

\section{PENDAHULUAN}

Hama penggerek buah kopi (Hypothenemus hampei Ferrari) merupakan salah satu hama utama pada tanaman kopi, karena hama ini selalu menyerang dan menyebabkan menurunnya produksi dan mutu kopi di Indonesia dan bahkan juga terjadi di seluruh negara penghasil kopi. Penggerek buah kopi (H. hampei) menyerang perkebunan kopi bermula dari tanaman yang berada di daerah yang paling lembab atau tanaman penaungnya terlalu rimbun. Jika tidak ditanggulangi dengan baik, maka hama ini akan menyebar sampai ke seluruh tanaman kopi di perkebunan (Kalshoven, 1981) 
Terdapat beberapa macam jenis kerusakan yang mungkin dapat ditimbulkan oleh serangan H. hampei, seperti buah menjadi tidak berkembang, berubah warna menjadi kuning kemerahan dan akhirnya gugur, serta buah berlubang yang pada akhirnya mengakibatkan penurunan kuantitas dan kualitas produksi (Zahro'in, E. dan Y, 2013)

H. hampei biasanya menggerek buah muda dan buah yang mulai mengeras, yaitu posisi di sekitar diskus (pusar) buah kopi. Penggerek buah kopi masuk kedalam buah kopi dengan cara membuat lubang di sekitar diskus. Jika buah masih muda akan menggakibatkan buah muda gagal berkembang dan akan gugur, namun jika buah sudah mulai mengeras akan mengakibatkan biji kopi cacat berlubang. Biji kopi yang cacat sangat berpengaruh negatif terhadap susunan senyawa kimianya, terutama pada kafein dan gula pereduksi. Biji berlubang merupakan salah satu penyebab utama kerusakan mutu kimia, sedangkan citarasa kopi dipengaruhi oleh kombinasi komponen-komponen senyawa kimia yang terkandung dalam biji (Firdaus, 2018).

Dengan demikian hama penggerek buah kopi merupakan hama yang sangat merusak dan operlu dikendalikan (Rahardjo, 2017). Penelitian ini bertujuan untuk mengetahui keragaman serangan H. hampei pada beberapa sentra produksi kopi robusta di Provinsi Lampung. Hipotesis yang diajukan dalam penelitian ini adalah bahwa intensitas serangan $H$. hampei pada sentra produksi kopi robusta di Provinsi Lampung sangat beragam dan dipengaruhi oleh ketinggian tempat.

\section{METODE PENELITIAN}

Penelitian dilaksanakan di empat kabupaten dan tiga kecamatan pada masing- masing kabupaten yang merupakan sentra produksi kopi robusta di Provinsi Lampung yaitu Kabupaten Lampung Barat (Kecamatan Gedung Surian, Kebun Tebu, dan Sumberjaya), Kabupaten Tanggamus (Kecamatan Gisting, Sumberejo, dan Gunung Alip), Kabupaten Lampung Utara (Abung Tinggi, Abung Barat, dan Abung Kunang), dan Kabupaten Way Kanan (Kecamatan Banjit, Gunung Labuhan, dan Kasui) pada bulan April sampai September 2019.

Alat yang diperlukan adalah mangkuk, pena, kertas, dan lup. Bahan yang diperlukan dalam penelitian ini adalah buah kopi hasil panen.

Pengambilan sampel dalam penelitian ini dilaksanakan dengan metode acak berdasarkan wilayah (Area Random Sampling). Sampel diambil berdasarkan masa panen (musim) pada 3 (tiga) kecamatan terpilih dalam wilayah kabupaten yang telah ditetapkan. Pengambilan contoh (sampel) akan diulang sebanyak 3 (tiga) kali. Pada setiap kabupaten dipilih 3 (tiga) kecamatan yang masyarakatnya mayoritas berusahatani kopi robusta. Pada setiap kecamatan terpilih diobservasi 1 (satu) orang petani yang sedang melakukan panen. Pada tumpukan hasil panen petani terpilih tersebut diambil sampel pengamatan dengan menggunakan mangkuk. Dari sejumlah buah kopi yang terambil dengan mangkuk dihitung secara manual jumlah biji yang berlubang (A) dan tidak berlubang (B). Kemudian persentase atau intensitas serangan dihitung dengan menggunkan rumus sebagai berikut: $\frac{\mathrm{A}}{\mathrm{A}+\mathrm{B}} \times 100 \%$.

Data hasil penelitian diolah dengan sidik ragam menggunakan uji Fisher (SAS Institute 1990). Nilai tengah perlakuan dibandingkan dengan uji BNT (Beda Nyata Terkecil) dengan $\alpha=0,05$. Untuk mengetahui kecenderungan hubungan (korelasi) intensitas serangan hama H. hampei dengan tinggi tempat dan suhu lingkungan, maka dihimpun juga data suhu maksimum, suhu minimum serta tinggi tempat lokasi penelitian yang bersumber dari BMKG Lampung.

\section{HASIL DAN PEMBAHASAN}

Berdasarkan Uji Fisher diketahui bahwa di 12 (dua belas) kecamatan pada empat kabupaten sentra produksi tanaman kopi robusta Provinsi Lampung, intensitas serangan hama $H$. hampei cukup beragam yang berkisar antara $6,30 \%$ sampai $20 \%$ dan diantaranya terdapat perbedaan yang nyata (Tabel 1 ). 
Ervandari, dkk : Keragaman Intensitas Serangan Hama Penggerek Buah Kopi (Hypothenemus Hampei Ferrari.)....

Tabel 1. Uji nilai tengah intensitas serangan hama $H$. hampei di empat kabupaten sentra produksi kopi M robusta yang diteliti

\begin{tabular}{llcc}
\hline \multirow{2}{*}{ Kabupaten } & Kecamatan & \multicolumn{2}{c}{ Intensitas serangan H. hampei } \\
\cline { 3 - 4 } & & & $(\%)$ \\
\hline Lampung Barat & Gedung Surian & 20,00 & $\mathrm{a}$ \\
& Kebun Tebu & 19,23 & $\mathrm{ab}$ \\
\multirow{2}{*}{ Tanggamus } & Sumber Jaya & 18,95 & $\mathrm{~b}$ \\
& Gisting & 13,12 & $\mathrm{c}$ \\
& Sumberejo & 12,91 & $\mathrm{c}$ \\
Lampung Utara & Gunung Alip & 13,35 & $\mathrm{c}$ \\
& Abung Tinggi & 6,30 & $\mathrm{~d}$ \\
& Abung Barat & 6,56 & $\mathrm{~d}$ \\
\multirow{3}{*}{ Way Kanan } & Abung Kunang & 6,34 & $\mathrm{~d}$ \\
& Banjit & 7,09 & $\mathrm{~d}$ \\
& Gunung Labuhan & 6,99 & $\mathrm{~d}$ \\
& Kasui & 7,07 & $\mathrm{~d}$ \\
& & & BNT 5\% \\
\hline
\end{tabular}

Berdasarkan uji nilai tengah (Tabel 1) diketahui bahwa, intensitas serangan H. hampei di Kecamatan Gedung Surian tidak berbeda nyata dengan Kecamatan Kebun Tebu, namun berbeda nyata dengan intensitas serangan H. hampei di Kecamatan Sumberjaya, Gisting, Sumberejo, Gunung Alip, Abung Tinggi, Abung Barat, Abung Kunang, Banjit, Gunung Labuhan dan Kecamatan Kasui. Intensitas serangan H. hampei di Kecamatan Gisting, Sumberejo dan Gunung Alip tidak berbeda nyata satu sama lain, namun berbeda nyata dengan intensitas serangan H. hampai di Kecamatan Gedung Surian, Kebun Tebu, Sumberjaya, Abung Tinggi, Abung Barat, Abung Kunang, Banjit, Gunung Labuhan dan Kecamatan Kasui. Intensitas serangan H. hampei di Kecamatan Abung Tinggi, Abung Barat, Abung Kunang, Banjit, Gunung Labuhan, dan Kecamatan Kasui tidak berbeda nyata satu sama lain

Setelah diamati lebih lanjut terlihat bahwa intensitas serangan hama $H$. hampei berkorelasi positif dengan ketinggian tempat. Grafik yang menggambarkan hubungan antara ketinggian tempat dan intensitas serangan hama H. hampei dapat dilihat pada Gambar 1.

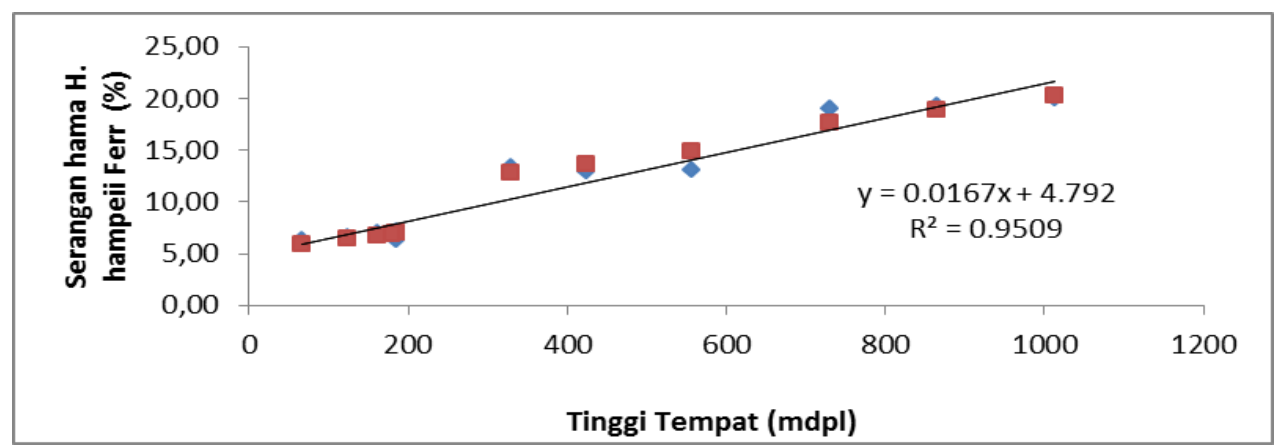

Gambar 1. Grafik hubungan ketinggian tempat dengan intensitas serangan hama H. hampei.

Pada Gambar 1 dapat diketahui bahwa ketinggian suatu tempat berpengaruh nyata positif terhadap persentase serangan hama $H$. hampei pada taraf nyata $\alpha 0,05$ dengan nilai koefisien regresi 0,9509 yang 
artinya berpengaruh sangat kuat. Berdasarkan grafik tersebut terlihat bahwa semakin tinggi suatu tempat, maka semakin tinggi pula persentase serangan hama $H$. hampei.

Menurut Prakoswo, Ariffin, \& Tyasmoro, (2018) dan Cycle, (2012) ketinggian suatu tempat atau wilayah akan mempengaruhi suhu udara, karena semakin tinggi suatu wilayah maka proses kondensasi akan menjadi cepat dan suhu akan menjadi rendah. Rata-rata penurunan suhu udara di Indonesia $0,5-0,6{ }^{\circ} \mathrm{C}$ tiap kenaikan 100 meter. Selain mempengaruhi suhu, ketinggian suatu tempat juga berpengaruh terhadap kelembaban udara dan angin yang mempengaruhi penyebaran serangga. Ketinggian tempat juga erat kaitannya dengan perubahan suhu udara yang memegang peranan penting dan menjadi faktor pembatas karena mempengaruhi proses metabolisme dan kehidupan serangga seperti aktivitas makan, pertumbuhan dan perkembangannya.

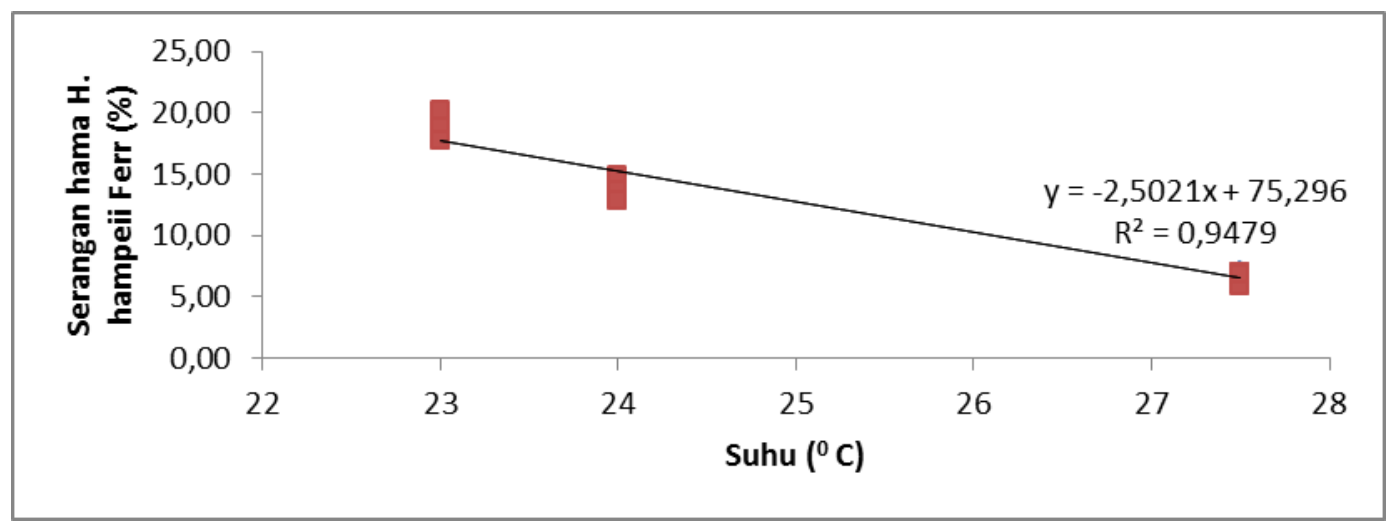

Gambar 2. Grafik hubungan suhu dengan intensitas serangan hama H. hampei

Setelah diamati lebih lanjut terlihat bahwa intensitas serangan hama $H$. hampei berpengaruh negatif dengan suhu tempat. Grafik yang menggambarkan hubungan antara suhu tempat dan intensitas serangan hama H. hampei dapat dilihat pada Gambar 2. Pada Gambar 2 terlihat bahwa suhu di suatu tempat berpengaruh negatif terhadap persentase serangan hama $H$. hampei pada taraf nyata $\alpha 0,05$ dengan nilai koefisien regresi 0,9479, yang artinya berhubungan sangat kuat. Hal ini memperlihatkan bahwa semakin rendah suhu suatu tempat, maka serangan hama H. hampei semakin tinggi. Berdasarkan Gambar 2, terlihat bahwa pada wilayah dengan intensitas serangan hama $H$. hampei tertinggi yaitu di Kecamatan Gedung Surian memiliki suhu rata-rata terendah $\left(23^{\circ} \mathrm{C}\right)$ dengan intensitas serangan hama $H$. hampei tertinggi (15 20\%). Sedangkan suhu rata- rata tertinggi $26{ }^{\circ} \mathrm{C}$ dengan intensitas serangan terendah yaitu 5\%. Tingginya intensitas serangan di Kecamatan Gedung Surian ini dipengaruhi oleh ketinggian tempat. Daerah ini memiliki ketinggian tempat $1.013 \mathrm{mdpl}$ yang merupakan daerah dengan ketinggian tempat yang paling tinggi dibanding dengan daerah pengamatan lainnya sehingga di Kecamatan Gedung Surian daur hidup H. hampei semakin lama. Hal ini berhubungan dengan daur hidup hama H. hampei dari fase telur sampai imago akan semakin panjang. Hal sebaliknya terjadi pada daerah dengan ketinggian tempat yang lebih rendah, maka siklus hidup serangga akan semakin singkat. Menurut Susilo, A, (2008) menyatakan bahwa serangan hama H. hampei lebih tinggi pada kisaran ketinggian tempat $500-1.000$ mdpl daripada ketinggian kurang dari $500 \mathrm{mdpl}$ atau lebih dari $1.000 \mathrm{mdpl}$. Semakin tinggi tempat, maka semakin tinggi pula intensitas serangan hama H. hampei.

Menurut Syahnen., et al, (2008) pada serangan berat hama H. hampei dapat menimbulkan kehilangan hasil sampai 75\%. H. hampei menyerang buah kopi mulai dari buah yang masih hijau, matang susu, sampai panen. Hal ini juga diungkapkan oleh (Arief $\mathrm{M}, \mathrm{C}, \mathrm{W}, 2011$ ) bahwa serangan $H$. hampei dapat menurunkan mutu kopi dan penurunan produksi hingga 20\% - 30\%. Prastowo, et all (2010) menambahkan bahwa tindakan pengendalian sudah perlu dilakukan bila intensitas serangan hama $H$. hampei lebih dari $10 \%$. 
Intensitas serangan hama $H$. hampei erat kaitannya dengan suhu lingkungan, karena perubahan suhu sangat berpengaruh terhadap dinamika populasi serangga seperti fisiologi serangga, kelimpahan serangga, distribusi serangga, dan dimensi serangga (Shi, et all 2011). Pada dasarnya suhu lingkungan sangat mempengaruhi metabolisme serangga yang berhunbungan dengan kemampuan bertahan hidup, sehingga dapat mempengaruhi kelimpahan serangga (Caspers, 1977) Hal tersebut menggambarkan respon serangga terhadap lingkungannya. Serangga sangat sensitif terhadap variasi perubahan lingkungan, khususnya serangga yang dapat terbang dan berpindah untuk menghindari naik turunnya suhu, kelembaban, zat kimia atau faktor abiotik lainnya serta menghindari kondisi yang merugikan (Schowalter, 1996)

Thomson, et all, (2010) menyatakan bahwa serangga memilki kisaran suhu tertentu untuk perkembangan dan proses fisiologisnya, yang mana pada suhu tertentu aktivitas serangga tinggi dan akan berkurang (menurun) pada suhu yang lebih rendah. Fakta ini memperlihatkan bahwa suhu yang tidak mendukung akan memperpendek umur serangga.

\section{KESIMPULAN}

Ketinggian tempat mempengaruhi intensitas serangan hama $H$. hampeii dengan tingkat serangan tertinggi terdapat di Kecamatan Gedung Surian Kabupaten Lampung Barat yaitu 20,00 \% dan tingkat serangan terendah pada Kecamatan Abung Tinggi Kabupaten Lampung Utara yaitu 6,30\%, selain itu terdapat korelasi positif antara ketinggian tempat dengan tingkat serangan hama $H$. hampeii, namun terdapat korelasi negatif antara suhu suatu tempat dengan tingkat serangan hama H. hampeii.

\section{DAFTAR PUSTAKA}

Arief M, C, W., Mesin, T., Raminim, S dan Fazrin, R. (2011). Panduan Sekolah Lapangan Budidaya Kopi Konservasi. Conservation International Indonesia.

Caspers, H. (1977). Morris Rockstein (Editor): The physiology of insecta. Second edition. New York and London: Academic Press.; Volume II. 1974. 568 pp. ISBN 0-12-591602-7. \$ 38.00; Volume III. 1974. 517 pp. ISBN 0-12-591603. \$ 38.00. Internationale Revue Der Gesamten Hydrobiologie Und Hydrographie. https://doi.org/10.1002/iroh.1977.3510620118

Cycle, L. (2012). Sweetpotato Weevil, Cylas formicarius (Fabricius) (Coleoptera: Brentidae). SpringerReference, 1-5. https://doi.org/10.1007/springerreference_89633

Kalshoven, L. G. E. (1981). The Pest of Crops in Indonesia. Revised and Translated By P.A. Van der laan. Jakarta: PT. Ichtiar Baru-Van Hoeve.

Prakoswo, D., Ariffin, \& Tyasmoro, S. Y. (2018). The analyze of agroclimate in ub forest area malang district, east Java, Indonesia. Bioscience Research, 15(2), 918-923.

Prastowo, B., Elna, K., Rubijo., Siswanto., Chandra, I., J. (2010). Budidaya dan Pasca Panen Kopi. Bogor: Pusat Penelitian dan Pengembangan Perkebunan.

Rahardjo, P. (2017). Berkebun Kopi. Jakarta Timur.

Schowalter. (1996). Insect Ecology an Ecosystem Approach. New York: Academic Press.

Shi, P, Zhong. L, Sandhu. H. S, Ge. F, Xu. X, C. W. (2011). Population decrease of Scirpophaga incertulas (Walker) (Lepidoptera Pyralidae) under climate warming. Ecologi and Evolution, 2, 58-64.

Susilo, A, W. (2008). Ketahanan Tanaman Kopi (Coffea Spp) terhadap Hama Penggerek Buah Kopi ( Hypothenemus hampeii Ferr.). Review Penelitian Kopi Dan Kakao, Vol 24 (1), 1-14. 
Syahnen., Yenni, A dan Ida, R,T, S. (2008). Rintisan Metode Pengamatan Hama Penggerek Buah Kopi ( Hypothenemus hampeii Ferr.) di Kabupaten Dairi Sumatera Utara. Balai Besar Perbenihan Dan Proteksi Tanaman Perkebunan. Medan, Vol 28 (2), 100-110.

Thomson, L. J., Macfadyen, S., \& Hoffmann, A. A. (2010). Predicting the effects of climate change on natural enemies of agricultural pests. Biological Control. https://doi.org/10.1016/j.biocontrol.2009.01.022

Zahro'in, E. dan Y, Y. (2013). Hubungan Persentase Serangan Hama Penggerek Buah Kopi (Hypothenemus hampei Ferr. (Coleoptera: Scolytidae)) dengan Dugaan Kehilangan Hasil di Kecamatan Betara Tanjung Jabung Barat. Jurnal Media Pertanian., 1 (2):, 85 - 90. 